\section{Study on Mechanical Behavior of Banana Fiber Reinforced Epoxy Composites}

\author{
H. R. Radha ${ }^{1}$, P. V. Krupakara ${ }^{2}$, V. Latha ${ }^{1}$, R. Lakshmi ${ }^{1}$, K. Vinutha ${ }^{3}$ \\ ${ }^{1}$ Department of Chemistry, T John Institute of Technology, Bengaluru, Karnataka, India, ${ }^{2}$ Department of \\ Chemistry, Cambridge Institute of Technology, Bengaluru, Karnataka, India, ${ }^{3}$ Department of Chemistry, \\ East West Institute of Technology, Bengaluru, Karnataka, India
}

Address for correspondence: Dr. H. R. RADHA, Professor and Head, Department of Chemistry, T John Institute of Technology, Bangalore-83.

Keywords:

Mechanical properties, Natural fiber composites, Surface morphology

Received: $01^{\text {st }}$ February 2019 Accepted: 06 ${ }^{\text {th }}$ March 2019 Published: 21 ${ }^{\text {rd }}$ March 2019

\section{INTRODUCTION}

The world is as of now concentrating on alternate material source that is environment agreeable and biodegradable in nature. Due to the expanding natural concerns, biocomposite produced out of regular fiber and polymeric resin is one of the late advancements in business. The use of composite materials field is increasing gradually in engineering. Fiber reinforced polymer composites have numerous preferences due to minimal effort of creation and better quality contrast than perfect polymer tars. Satyanarayana et al. ${ }^{[1]}$ studied that natural fibers have numerous points of interest contrasted with glass fiber as natural fibers have low thickness; they are biodegradable and recyclable. Banana reinforced polymer composite has a high impact of fiber loading and length of fiber on the properties of composites. ${ }^{[1]}$ Kulkarni et al. ${ }^{[2-5]}$ studies show that banana fiber can obtain from fruit and stem of the plant and is abundantly cultivated. Many researchers have done investigations on different types of natural fibers such as cotton, bamboo, wheat, and barley to study the mechanical properties of composite materials. Merlini et al. ${ }^{[6,7]}$ have studied the effect of surface treatment on the chemical properties of banana fiber and reported that treated banana fiber gives higher shear interfacial stress and tensile strength when compared with the untreated fiber. Venkateshwaran et al. ${ }^{[8-10]}$ studied the mechanical properties of tensile and flexural strength of banana/ epoxy composite material. Thiruchitrambalam et al. ${ }^{[11]}$ have investigated the influence of fiber content and length on short banana fiber reinforced polyester composite material. They also studied the physical and mechanical behavior of banana fiber reinforced polymer composite and noticed that kraft mashed banana fiber material has better flexural strength. The banana and glass fiber biocomposites may be used to fabricate outdoor and indoor applications where high strength is not necessary and it can be considered as the replacement to wood materials and protect the forest resources. In this present work, to improve the mechanical properties, the banana fibers of different lengths are treated with different weight \% epoxy resin. The banana fibers are used as reinforcement in epoxy resin.

\section{MATERIALS AND METHODS}

\section{Chemical treatment}

Banana fiber was collected from local banana plant source, Bengaluru, India. The extracted banana fibers were subsequently 
sun-dried for $8 \mathrm{~h}$ and then dried in the oven for $24 \mathrm{~h}$ at $105^{\circ} \mathrm{C}$ to remove free water present in the fiber. The dried fiber was cut into lengths of 5, 10, and $15 \mathrm{~mm}$. Then, the dried fibers were treated with different weight $\%$ epoxy resin for $24 \mathrm{~h}$. The fibers are then washed thoroughly with distilled water. Fibers are then dried in oven for $2 \mathrm{~h}$ at $100^{\circ} \mathrm{C}$ to remove the moisture present in it.

\section{Matrix}

Epoxy resin and hardener are procured from Ciba Geigy India Ltd. As per the ASTM standards, the matrix is formed with nine different combinations untreated and treated fiber reinforced epoxy resin composite.

\section{PREPARATION OF THE COMPOSITE}

By hand lay-up technique, the composite is fabricated. The molds have been prepared with dimensions of $180 \mathrm{~mm} \times 180 \mathrm{~mm} \times 40 \mathrm{~mm}^{3}$. The banana fiber of different length has been mixed with matrix mixture with their respective values by simple mechanical stirring and mixtures were slowly poured into molds. The releasing agent has been used on the mold sheet which gives easy to composite removal from molds after curing the composites. A sliding roller has been used to remove the trapped air from the uncured composite and mold has been closed at temperature $30^{\circ} \mathrm{C}$ for $34 \mathrm{~h}$ duration. The constant load of $50 \mathrm{~kg}$ is applied on the mold, in which the mixture of the banana, epoxy resin, and hardener has been poured. After curing, the specimens were taken out from molds and the composite material is cut in suitable dimensions with the help of zig saw for mechanical tests as per the ASTM standards.

\begin{tabular}{ll}
\hline Designation & Composition \\
\hline C1 & Fiber length $(5 \mathrm{~mm})(10 \mathrm{wt} \%)+$ Epoxy $(90 \mathrm{wt} \%)$ \\
C2 & Fiber length $(5 \mathrm{~mm})(15 \mathrm{wt} \%)+$ Epoxy $(85 \mathrm{wt} \%)$ \\
C3 & Fiber length $(5 \mathrm{~mm})(20 \mathrm{wt} \%)+$ Epoxy $(80 \mathrm{wt} \%)$ \\
C4 & Fiber length $(10 \mathrm{~mm})(10 \mathrm{wt} \%)+$ Epoxy $(90 \mathrm{wt} \%)$ \\
C5 & Fiber length $(10 \mathrm{~mm})(15 \mathrm{wt} \%)+$ Epoxy $(85 \mathrm{wt} \%)$ \\
C6 & Fiber length $(10 \mathrm{~mm})(20 \mathrm{wt} \%)+$ Epoxy $(80 \mathrm{wt} \%)$ \\
\hline
\end{tabular}

\section{Tensile test}

Figure 1 shows the specimen prepared for tensile test. The specimen size was $150 \times 15 \mathrm{~mm}^{2}$ and gauge length was $70 \mathrm{~mm}$. The tensile strength was tested in Instron machine to measure the force required to break a polymer composite specimen and the extent to which the specimen stretches or elongates to that breaking point. Here, Figure 2 indicates a broken piece during the tensile test.

\section{Flexural test}

The capacity of a material to resist deformation under the load applied is known as flexural strength. The specimen dimension for flexural test was $100 \mathrm{~mm} \times 15 \mathrm{~mm} \times 70 \mathrm{~mm}$. Due to inter laminar shear, fiber failure takes place, which is observed in a three point bend test. Using Universal Testing Machine Instron 1195, the test is conducted. The loading arrangement for flexural strength test is shown in Figure 3.

Flexural MR is about 10-20\% of compressive strength depending on the size, volume, and type of coarse aggregate used. Anyway, the best correlation for specific materials is obtained by laboratory tests for given materials and mix design. The maximum fiber stress at failure on the tension side of a flexural specimen is considered the flexural strength of the material. Thus, using a homogeneous beam Equation (1), the flexural strength in a three-point flexural test is given by,

$$
\sigma_{\mathrm{f}}=\frac{3 \mathrm{FL}}{2 \mathrm{bd}^{2}}
$$

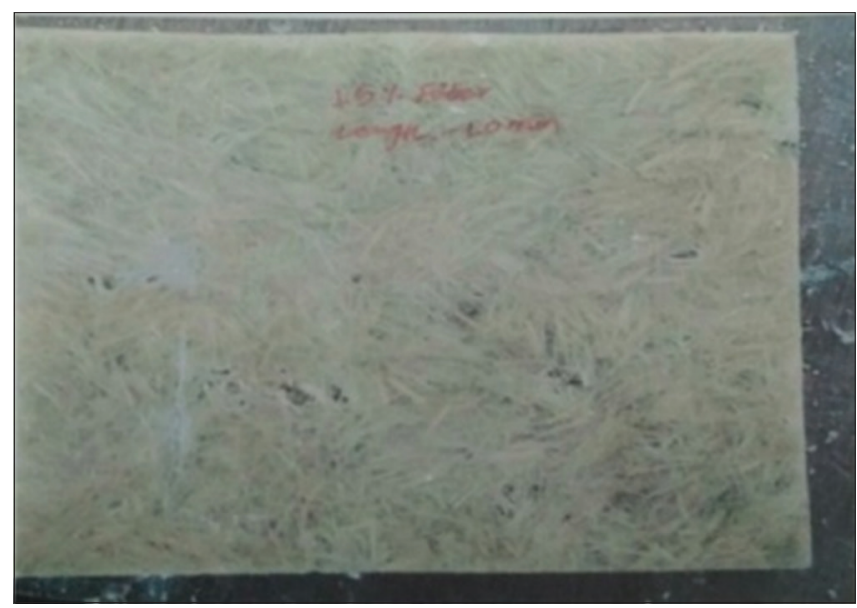

Figure 1: Tensile test specimens

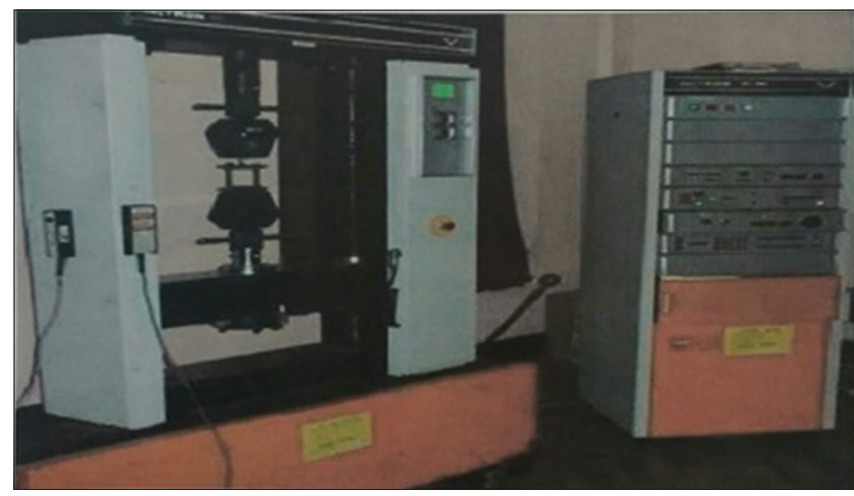

Figure 2: Tensile specimen in Instron Machine

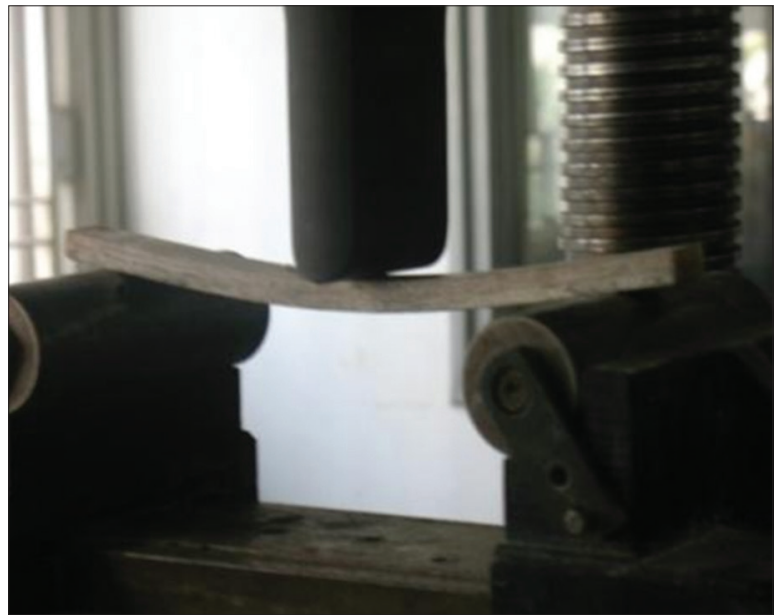

Figure 3: Flexural test arrangement 
Where,

$\mathrm{P}_{\max }=$ Maximum load at failure

$\mathrm{b}=$ specimen width

$\mathrm{h}=$ Specimen thickness and

$\mathrm{L}=$ Spcimen length between the two support points

\section{Impact test}

Impact is a single-point test that measures a material resistance to impact from a swinging pendulum. Impact is defined as the kinetic energy needed to initiate fracture and continue the fracture until the specimen is broken. Figures 4-6 shows the impact testing observation during the experimental work.

\section{Hardness test}

Hardness is the ability to oppose the indentation, which is obtained by measuring the stable depth of the indentation. In the Vickers hardness test, a square base pyramid shaped diamond is used for testing.

Fabricated composite was cut in a dimension of $20 \mathrm{~m} \times$ $20 \mathrm{~mm}$ for hardness test. The hardness test was conducted in Vickers hardness test machine. $0.3 \mathrm{~kg}$ of load was applied on the composite and the load was held for $10 \mathrm{~s}$. The experimental setup for hardness test is shown in Figure 5.

\section{RESULTS AND DISCUSSIONS}

This chapter deals with the mechanical properties of the treated/untreated banana fiber/epoxy and treated/ un-treated banana fiber composites prepared for this present investigation.

\section{Mechanical properties of composites}

Mechanical properties of composites such as flexural strength, tensile strength, hardness, and impact strength have been investigated. The mechanical property of the composites mainly depends on fiber content and length.

Influence of fiber parameters on tensile strength

The influence of fiber length and loading on tensile properties of composites is shown in Figure 6. It has been observed that the tensile strength of composites increases with an increase in fiber length and loading.

\section{Influence of Fiber parameters on flexural Strength}

Figure 7 shows that, the flexural strength of the fabricated composites increases up to $10 \mathrm{~mm}$ of fiber length and then decreases. When fiber loading increases, then flexural strength increases up to fiber loading $15 \%$ and then decreases. The maximum flexural strength is observed when fiber length is 10 $\mathrm{mm}$ and loading is $15 \%$.

\section{Influence of fiber parameters on impact strength}

Figure 8 shows that impact energy increases with an increase in fiber length. It also shows that the impact energy increases with increase in fiber loading. Maximum impact energy is absorbed by the fiber length material of $15 \mathrm{~mm}$ and $20 \%$ of fiber content.

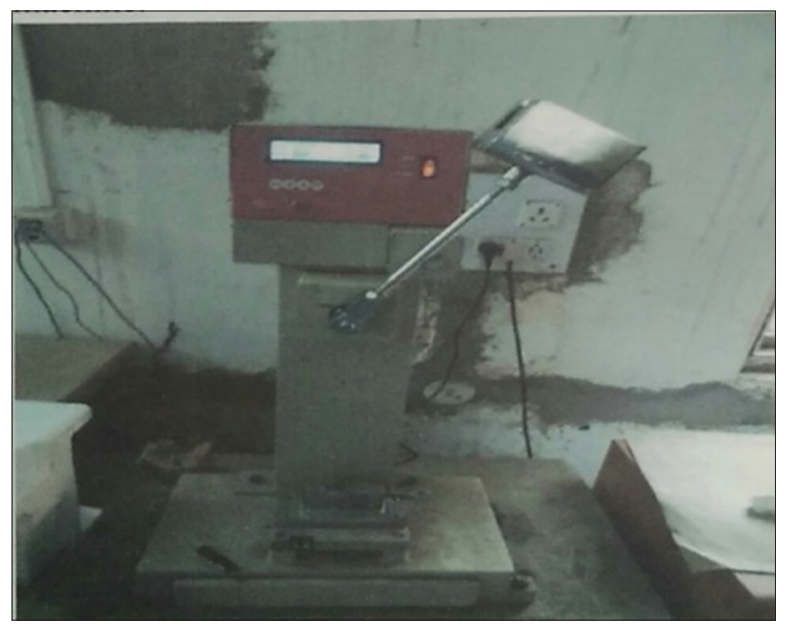

Figure 4: Impact testing of the specimen

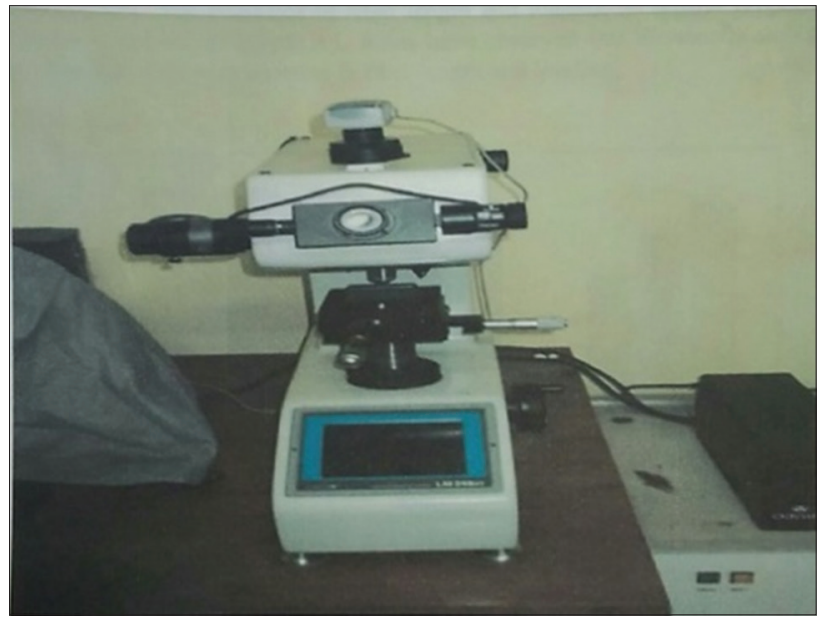

Figure 5: Experimental setup for Hardness testing of the specimen

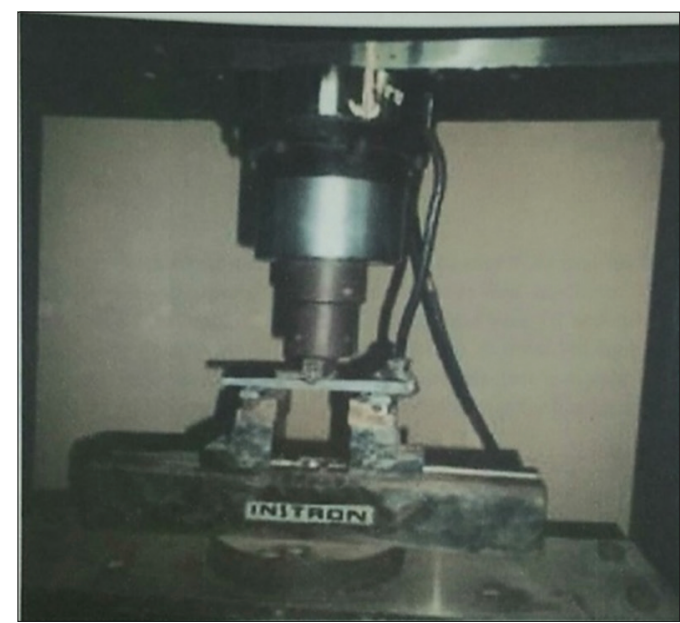

Figure 6: Three point bend test loading arrangement for Impact strength test

Influence of fiber parameters on hardness

Figure 8 shows that the hardness value increases with an increase in fiber length and it is maximum at $10 \mathrm{~mm}$ fiber 


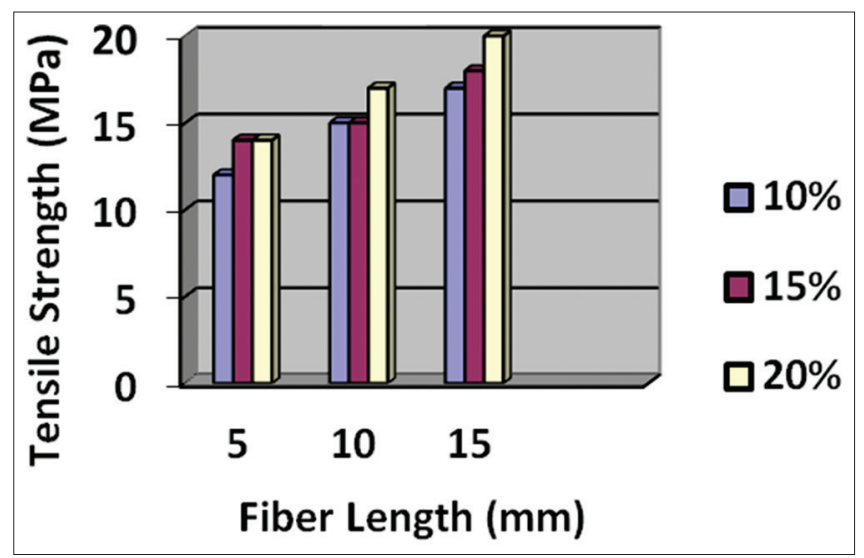

Figure 7: Influence of fiber parameters on tensile strength

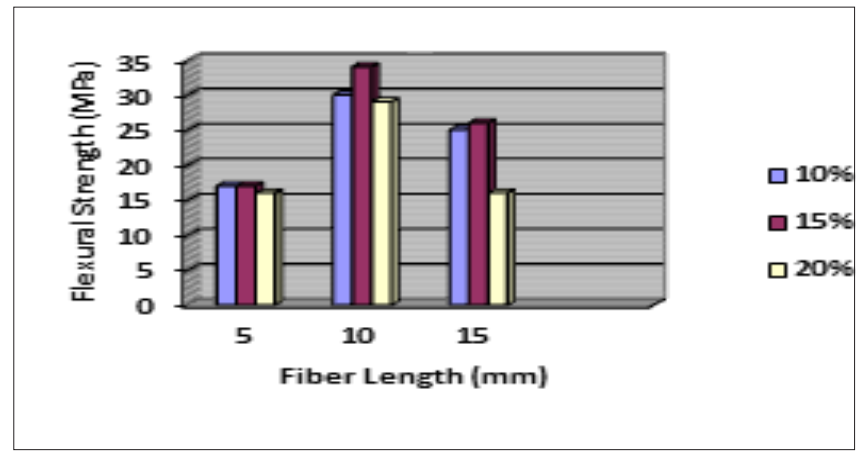

Figure 8: Influence of fiber parameters on flexural strength

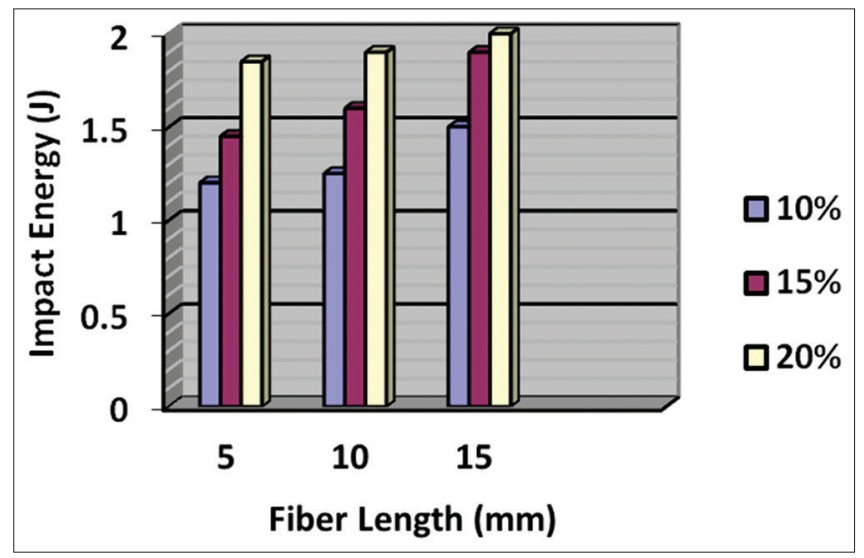

Figure 9: Influence of fiber parameters on Impact strength

length. However, the hardness value increase with increase in fiber loading up to $15 \mathrm{wt} \%$ and then the hardness value decreases. Table 1.

Observations of tensile properties are presented in

\section{SURFACE MORPHOLOGY}

Scanning electron microscope (SEM) images of untreated, alkali-treated fiber composite specimens are shown in Figures 9 and 10. Figure 11 shows the SEM of untreated composite after tensile test, and it reveal that the arrangements

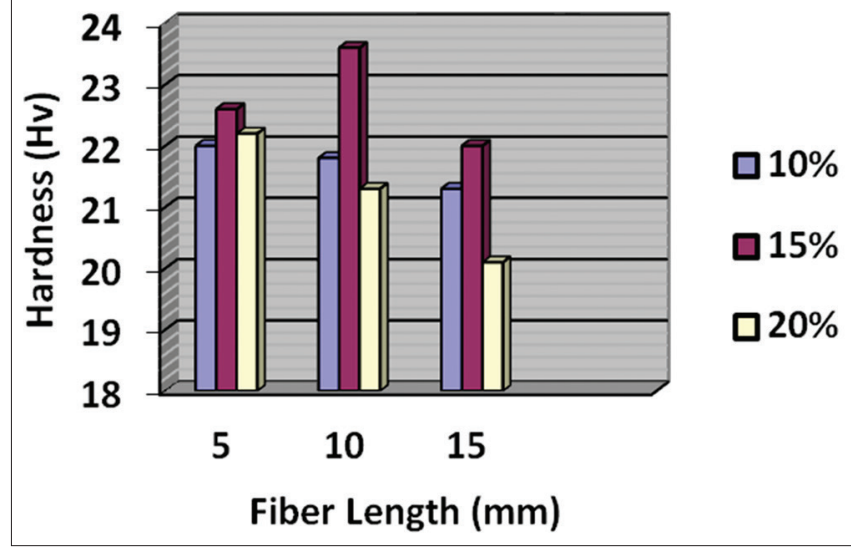

Figure 10: Influence of fiber parameters on Hardness

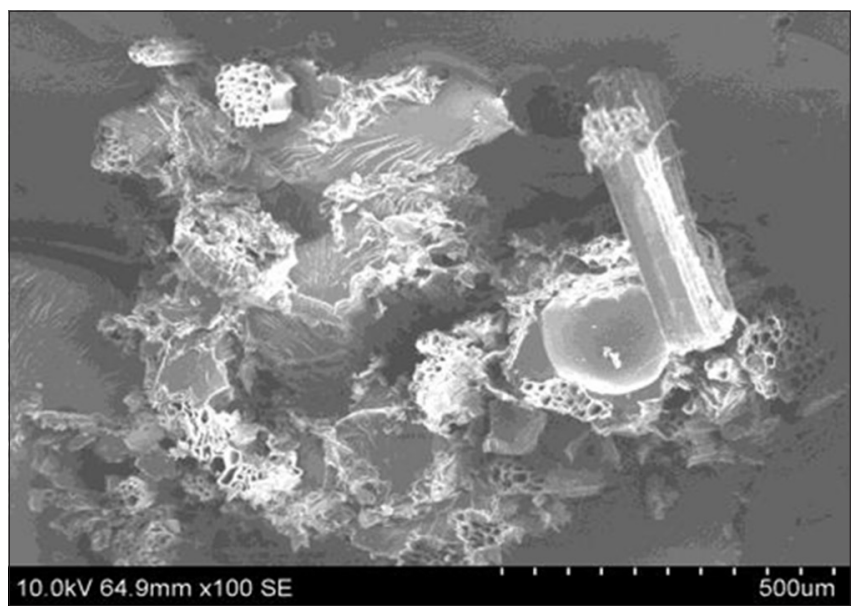

Figure 11: Untreated scanning electron microscope image $(\times 500)$ of banana fiber epoxy composite

of fiber are not dense and voids are present in it, so mechanical properties yield poor in this category.

Figure 12 is the SEM view of alkali-treated banana fiber composite sample after the tensile investigations. This image reveals that treatment has improved the property by adhesion between fiber and matrix which turn improved the mechanical strength. From the image, we can say that the distribution of hybrid resin is dominated the fiber effect. Hence, the results compared to the treated fiber shows a better result in these investigations.

\section{CONCLUSION}

In this work, mechanical properties of untreated/alkalitreated banana fiber/epoxy and untreated/alkali-treated banana fiber composites were investigated. The tensile, flexural, impact, and hardness properties of the composites as a function of fiber content are analyzed.

The fabrication of banana fiber epoxy-based composites with different loading of fiber and different lengths of the fiber is possible by hand lay-up process. From the current experiment results, it has been observed that fiber loading and length have major effect on the mechanical properties of composites such as tensile strength, flexural strength, impact strength, and hardness. 


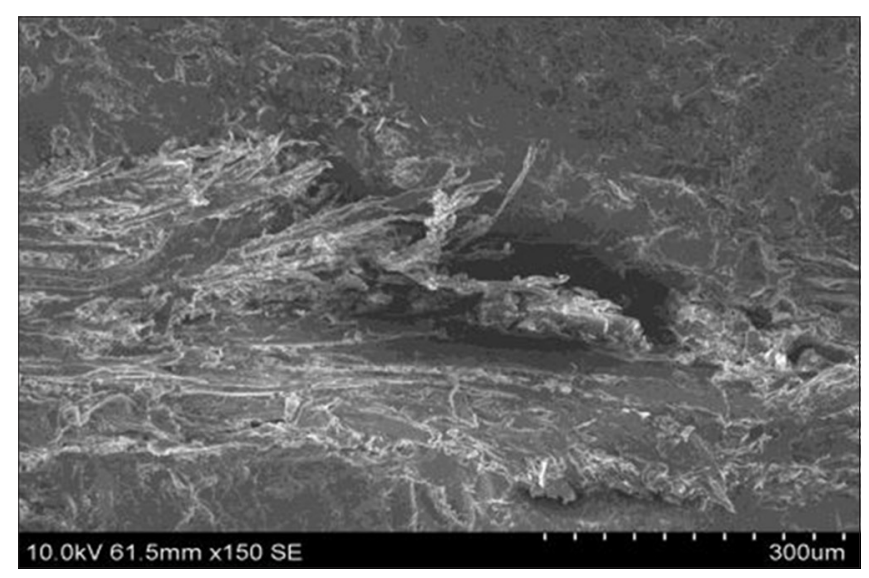

Figure 12: Alkali treated scanning electron microscope image $(\times 300)$ of banana fiber epoxy composite

It has been observed that the better mechanical properties found for composites reinforced with $10 \mathrm{~mm}$ fiber with $15 \%$ fiber loading

\section{SCOPE FOR FURTHER STUDIES}

This work can be further extended by preparing hybrid composites using different reinforcements in varying proportions and various mechanical properties of these composites can be compared.

\section{REFERENCES}

1. Satyanarayana KG, Sukumaran K, Pavithran C, Mukherjee PS, Pillai SG. Natural fiber-polymer composittes. Cem Concr Compos 1990;12:117-36.

2. Kulkarni AG, Rohatgi PK, Satyanarayana KG, Sukumaran K, Pillai SG. Fabrication and properties of natural fiber reinforced polymer composites. Composites 1986;17:329-33.
3. Aziz MA, Mansur MA. Study of bamboo-mesh reinfoorced cementcomposites. Int $\mathrm{J}$ Cem Compos Lightweight Concr 1983;5:165-71.

4. Mohini MS, Muhammad P. Carbon storage potential in natural fiber composites. Resour Conserv Recycl 2003;39:325-40.

5. Shibata S, Cao Y, Fukumoto I. Lightweight laminate composites made from kenaf and polypropylene fibres. Polym Test 2006;25:142-8.

6. Merlini C, Soldi V, Barra GM. Influence of fiber surface treatment and length on physico-chemical properties of short random banana fiber-reinforced castor oil polyurethane composites. Polym Test 2011;30:833-40.

7. Wambua P, Ivens J, Verpoest I. Natural fibres: Can they replace glass in fibre reinforced plastics? Compos Sci Technol 2003;63:1259-64.

8. Venkateshwaran N, Perumal AE, Jagatheeshwaran MS. Effect of fiber length and fiber content on mechanical properties of banana fiber/epoxy composite. J Reinforced Plast Compos 2011;30/19:1621-7.

9. Venkateshwaran N, Perumal AE, Alavudeen A, Thiruchitrambalam M. Mechanical and waterabsorption behaviour ofbanana/sisal reinforced hybrid composites. Mater Des 2011;32/7:4017-21.

10. Venkateshwaran N, Perumal AE. Banana fiber reinforced polymer composites-a review. J Reinforced Plast Compos 2010;29/15:2387-96.

11. Thiruchitrambalam M, Alavudeen A, Athijayamani A, Venkateshwaran N, Perumal AE. Improving mechanical properties of banana/kenaf polyester hybrid composites using sodium laulryl sulfate treatment. Mater Phys Mech 2009;9:165-73.

Cite this article: Radha HR, Krupakara PV, Latha V, Lakshmi R, Vinutha K. Study on Mechanical Behavior of Banana Fiber Reinforced Epoxy Composites. Asian J Mult-Disciplinary Res 2019:5(1):12-16.

Source of Support: Nil, Conflict of Interest: None declared. 